SCIENTIFIC REPORT

\title{
Intravitreal triamcinolone with photodynamic therapy for subfoveal choroidal neovascularisation in age related macular degeneration
}

\author{
E Rechtman, R P Danis, L M Pratt, A Harris
}

Br J Ophthalmol 2004;88:344-347. doi: 10.1136/bjo.2003.027177

Aims: To report the effects of intravitreal triamcinolone acetonide (iTAAC) injections as an adjunctive treatment to photodynamic therapy (PDT) with verteporfin for new subfoveal choroidal neovascularisation (CNV) in age related macular degeneration (AMD).

Methods: We retrospectively reviewed the records of all AMD patients who had iTAAC within 6 weeks of their first PDT and had a follow up of one year or longer. The proportion of eyes after one year follow up that lost or gained $\geqslant 15$ and $\geqslant 30$ ETDRS letters, baseline and one year lesion greatest linear dimension (GLD), number of PDTs, and side effects were assessed.

Results: Fourteen patients were evaluated. Eleven received one initial combined treatment and three received an additional combined treatment after 6 months. Median follow up was 18 months (range 12 to 25 months). Overall, $7 \%$ gained $\geqslant 30$ letters, $50 \%$ maintained stable vision, 14\% lost 15-29 letters, and $29 \%$ lost $\geqslant 30$ letters. Overall, mean GLD increased from 2580 (SD 1088) $\mu \mathrm{m}$ to 3946 (SD 1503) $\mu \mathrm{m}(\mathrm{p}=0.01)$. The mean number of PDTs during the first year was 2.57. Side effects were mild intraocular pressure elevation in $28.5 \%$ and cataract progression in $50 \%$ of phakic eyes.

Conclusions: iTAAC with PDT in AMD was found to be relatively safe and had reasonable results for lesions with some classic component.

C urrently, photodynamic therapy (PDT) with verteporfin and laser photocoagulation are the only proved treatments for subfoveal choroidal neovascularisation $(\mathrm{CNV})$ lesions in eyes with neovascular age related macular degeneration (AMD). ${ }^{1-6}$ Triamcinolone acetonide is a commonly used steroid for treating ocular inflammation by peribulbar and sub-Tenon's injections. ${ }^{7}$ Triamcinolone and other steroids, have been shown to be effective inhibitors of neovascularisation in animal models, ${ }^{8-11}$ and are among the most potent anti-angiogenic drugs known. ${ }^{12}$ Several small studies have found $4 \mathrm{mg}$ intravitreal triamcinolone acetonide (iTAAC) to be relatively safe and to have favourable effects on neovascular AMD. ${ }^{73-15}$ However, a recently published randomised clinical trial of a single $4 \mathrm{mg}$ iTAAC injection for subfoveal and juxtafoveal neovascular AMD did not show a reduced risk of moderate or severe visual loss during the first year. ${ }^{16}$ Another study has recently reported the beneficial effects of $25 \mathrm{mg}$ iTAAC injection in neovascular AMD patients. ${ }^{17}$ No published article (as of July 2003) has reported the safety and effects of iTAAC combined with PDT on eyes with neovascular AMD.
This retrospective cohort study evaluates the safety and visual outcome of iTAAC injections together with multiple PDT treatments for new subfoveal CNV caused by AMD.

\section{METHODS}

We conducted a retrospective analysis of the clinical records of all Indiana University AMD patients who received $4 \mathrm{mg}$ iTAAC injections $(0.1 \mathrm{ml}$, (Kenalog-40, Bristol-Meyer Squibb:Princeton, NJ, USA) $40 \mathrm{mg} / \mathrm{ml}$ ) for new subfoveal CNV within 6 weeks of their first PDT. These patients were offered the iTAAC/PDT combined treatment based on the ophthalmologist's experience with iTAAC, according to the Treatment of AMD with PDT (TAP) and Verteporfin In Photodynamic Therapy (VIP) study results, ${ }^{1-3}$ and, if eligible, after laser photocoagulation was refused. We included subjects who, in addition to the first iTAAC/PDT combined treatment, received a second combined treatment after 6 months follow up. All cases must have received no other treatment for their AMD and required a follow up of one year or more. Fourteen patients (9 female), mean age 80.3 (SD 8.1) years met our criteria and their clinical records were analysed. As part of the standard clinical care, these patients were seen in the retina clinic at Indiana University every 3 months ( \pm 2 weeks). At each visit, best corrected visual acuities (VA) were tested on either a front lit Bailey-Lovie chart at 10 feet, an ETDRS chart at $4 \mathrm{~m}$, or $1 \mathrm{~m}$, or, in cases of visual acuity worse than 20/800, with the Feinbloom chart. At each visit, fluorescein angiography (FA) to assess CNV leakage and a complete eye exam were performed.

iTAAC injection was given in an outpatient setting as previously described. ${ }^{7}{ }^{13}$ PDT with verteporfin treatment was given in the manner described in the TAP and VIP studies. ${ }^{1-3}$ For both treatment regimes a signed informed consent was obtained. In cases where both treatments were given at the same visit, PDT was administered first. Patients were followed closely for possible side effects and potential complications for the month following each iTAAC injection. Study parameters included the following: the proportion of eyes after one year follow up that lost or gained $\geqslant 15$ and $\geqslant 30$ ETDRS (or equivalent) letters; baseline and one year VA; baseline and one year lesion greatest linear dimension (GLD); the number of PDTs during the first year of follow up, and treatment side effects. Two tailed paired $t$ test was used to compare the visual acuity and GLD between baseline and one year visits. Fisher's exact test was used to compare the results between the group with "any classic" CNV component and

Abbreviations: $A M D$, age related macular degeneration; CNV choroidal neovascularisation; FA, fluorescein angiography; GLD, greatest linear dimension; iTAAC, intravitreal triamcinolone acetonide; PDT, photodynamic therapy; VA, visual acuity 


\begin{tabular}{|c|c|c|c|c|c|}
\hline & $\begin{array}{l}\text { Gained } \\
\geqslant 30 \\
\text { letters }\end{array}$ & $\begin{array}{l}\text { Gained } \\
15-29 \\
\text { lefters }\end{array}$ & $\begin{array}{l}\text { Stable VA } \\
( \pm 14 \\
\text { letters) }\end{array}$ & $\begin{array}{l}\text { Lost 15-29 } \\
\text { letters }\end{array}$ & $\begin{array}{l}\text { Lost } \geqslant 30 \\
\text { lefters }\end{array}$ \\
\hline $\begin{array}{l}\text { Predominantly } \\
\text { classic CNV }\end{array}$ & & & $\begin{array}{l}3 / 4 \\
(75 \%)\end{array}$ & & $\begin{array}{l}1 / 4 \\
(25 \%)\end{array}$ \\
\hline Minimally & & & $3 / 5$ & $1 / 5$ & $\begin{array}{l}1 / 5 \\
120 \%\end{array}$ \\
\hline $\begin{array}{l}\text { classic CNV } \\
\text { Any classic CNV }\end{array}$ & & & $\begin{array}{l}(60 \%) \\
6 / 9\end{array}$ & $\begin{array}{l}(20 \%) \\
1 / 9\end{array}$ & \\
\hline & & & $(67 \%)$ & $(11 \%)$ & $(22 \%)$ \\
\hline Pure occult CNV & $\begin{array}{l}1 / 5 \\
120 \%\end{array}$ & & $\begin{array}{l}1 / 5 \\
(20 \%)\end{array}$ & $\begin{array}{l}1 / 5 \\
20 \%\end{array}$ & $\begin{array}{l}2 / 5 \\
(40 \%)\end{array}$ \\
\hline
\end{tabular}

that with "pure occult" CNV, regarding the risk of developing moderate visual loss (loss of 15 or more letters). A p value of $<0.05$ was considered statistically significant.

\section{RESULTS}

Among the 14 subjects that met the study criteria, eleven (two predominantly classic (PC), four minimally classic $(\mathrm{MC})$, five pure occult $(\mathrm{PO})$ ) received one initial combined treatment and three (two PC, one $\mathrm{MC}$ ) received an additional combined treatment after 6 months. Median follow up was 18 months (range 12-25 months). At baseline, 36\% had systemic hypertension, $7 \%$ were smokers, $21 \%$ past smokers, and $42 \%$ were taking micronutrients. iTAAC was given 0.7 (SD 2.9) weeks before PDT. The proportion of eyes that lost or gained $\geqslant 15$ and $\geqslant 30$ ETDRS letters at the one year visit are summarised in table 1 . All three patients who received two iTAAC/PDT combined treatments maintained their VA $( \pm 14$ ETDRS letters) from baseline. Overall, VA changed from 70 (SD 15) ETDRS letters (Snellen equivalent 20/70) at baseline to 50 (SD 23) (20/200) ETDRS letters at one year visit $(p=0.02$; from $69($ SD 15) $(\sim 20 / 70)$ to $53($ SD 23) ( 20/160) for the subgroup with any classic component $(\mathrm{p}=0.04)$, and from 73 (SD 16) $(\sim 20 / 60)$ to 47 (SD 25) ( 20/250) for PO group $(p=0.22)$ ). The risk of developing moderate visual loss was not statistically different between the group with "any classic" CNV and that with "pure occult" CNV $(\mathrm{p}=0.58)$. Overall, GLD changed from 2580 (SD 1088) $\mu \mathrm{m}$ to 3946 (SD 1503) $\mu \mathrm{m}(\mathrm{p}=0.01$; from 2806 (SD 1066) $\mu \mathrm{m}$ to 3937 (SD 1423) $\mu \mathrm{m}$ for the subgroup with any classic component $(\mathrm{p}=0.2)$; from 3350 (SD 1069) $\mu \mathrm{m}$ to 4300 (SD 1548) $\mu \mathrm{m}$ for PO group $(p=0.09))$. The number (mean $(S D),($ median $))$ of PDTs during the first year (not including the 1 year visit) was 2.57 (SD 0.85), ((median 2.5) 2.9 (SD 0.8), (median 3) for the subgroup with any classic CNV; 2 (SD 0.7), (median 2) for $\mathrm{PO}$ ). At one year, six CNVs (one PC, three MC, two PO) showed leakage on FA. Transient intraocular pressure (IOP) elevation (to $22-28 \mathrm{~mm} \mathrm{Hg}$, after 2-3 months) occurred in four patients. Only one $(28 \mathrm{~mm} \mathrm{Hg})$ required antiglaucoma medication and all returned to normal IOP within one month. Cataract progressed in three of six phakic patients. One developed +3 posterior subcapsular opacification after 9 months. Two others developed cortical cataract after 6 and 9 months. All three also had an increase of nuclear sclerosis. Patients did not report floaters, although these were observed in some people during the first three months. No other side effects were observed. An example of a patient who received two iTAAC/PDT combined treatments is presented in figures 1 and 2 .

\section{DISCUSSION}

In this small retrospective study, iTAAC with PDT for subfoveal CNV due to AMD resulted in two probable side effects, transient IOP elevation and worsening of cataract, which could be both attributed to iTAAC. We can cautiously say that the one year visual outcomes found in this study are in the range of those found in the TAP ${ }^{1}$ and VIP ${ }^{3}$ studies $(33 \%$ of patients with "any classic" CNV lost $\geqslant 15$ letters $v 39 \%$ of the verteporfin treated eyes in the TAP; $60 \%$ of patients with "pure occult" CNV lost $\geqslant 15$ letters $v 51 \%$ of the verteporfin treated eyes in the VIP). Although it appeared that subjects with any classic CNV component had more favourable visual outcome after one year follow up, this difference did not

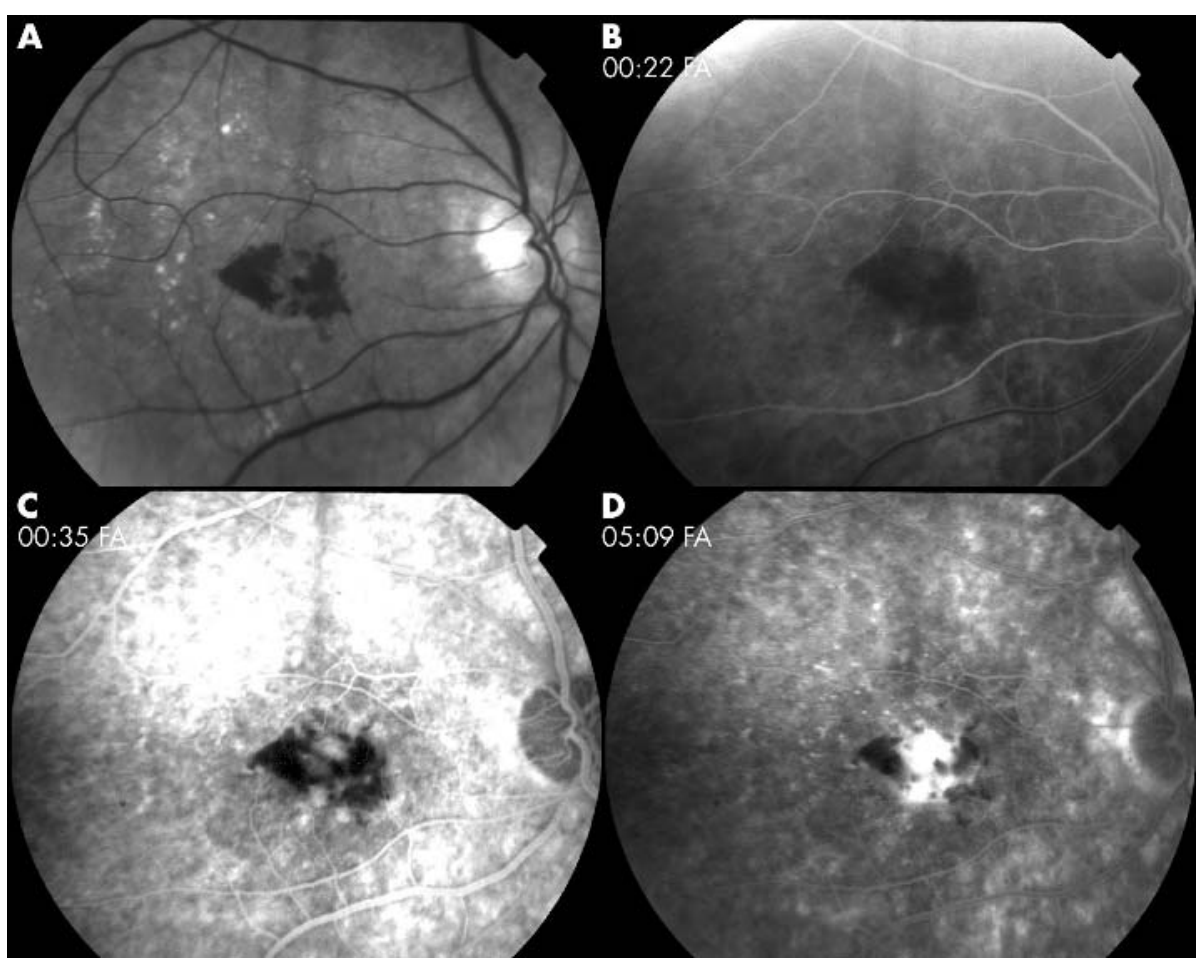

Figure 1 Eighty six year old man with systemic hypertension and pseudophakia, presented with new subfoveal choroidal neovascularisation due to age related macular degeneration in his right eye. At baseline, ETDRS letter score was 76 $(20 / 60+1)$ and lesion greatest linear dimension was $2490 \mu \mathrm{m}$. (A) Red free image at baseline. Early (B), mid (C), and late (D) phases of fluorescein angiography at baseline show predominantly classic lesion with subretinal haemorrhage occupying $60 \%$ of the total lesion area. 


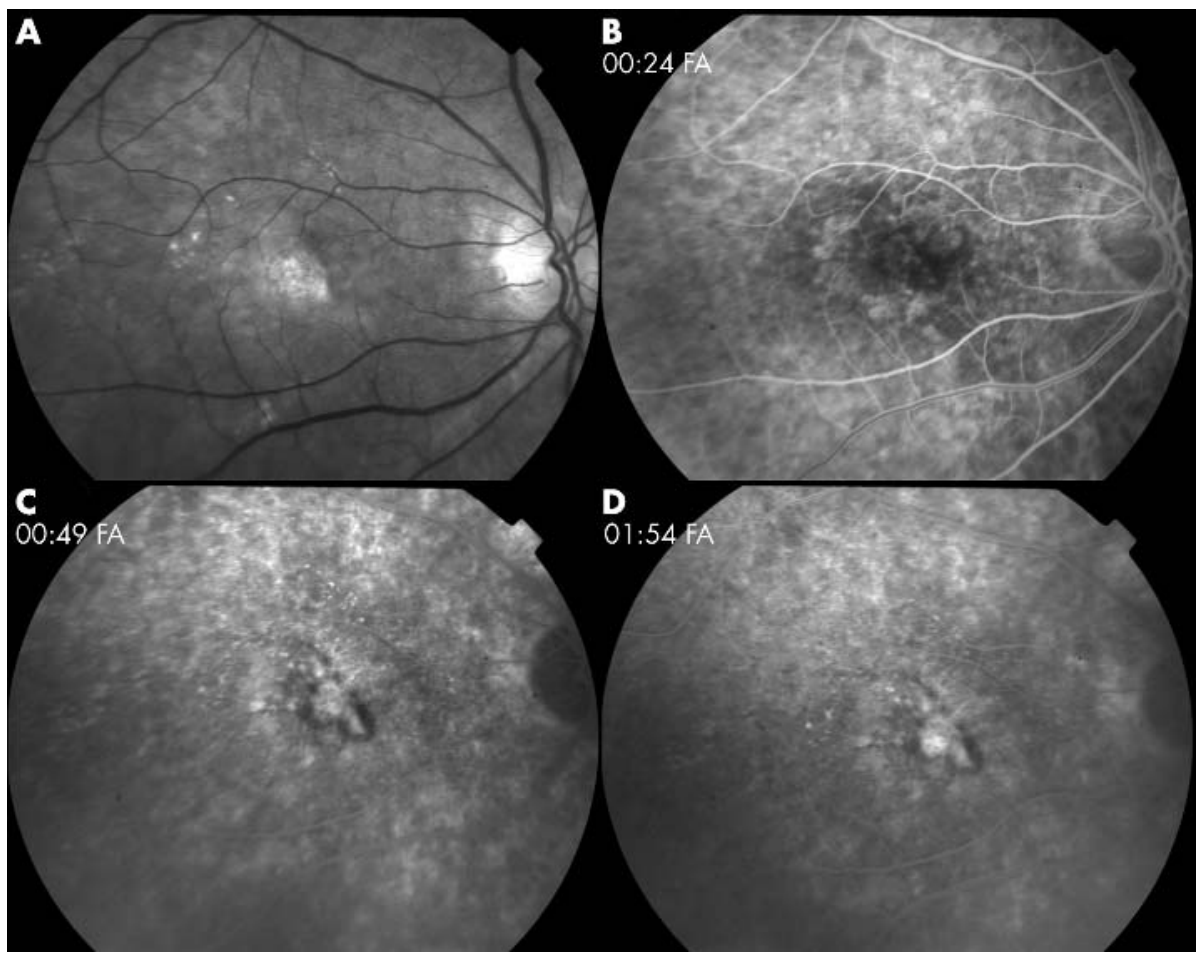

Figure 2 Fluorescein angiography (FA) of the same man as in figure 1, 12 month visit. Treatment consisted of two combined iTAAC/PDT treatments, given at the same visit, at baseline and after 6 months, with an additional PDT at the 3 month visit. (A) Red free image. Early (B), mid (C), and late (D) phases of FA show subfoveal lesion with subretinal fibrosis without late leakage. One year ETDRS letter score was 72 $(20 / 70+2)$. Intraocular pressure remained within normal limits throughout the follow up.

reach statistical significance. The three patients who received a second combined treatment after six months maintained their visual acuity $( \pm 14$ letters) after one year. These relatively favourable visual outcomes may be explained by iTAAC transient effect. iTAAC was found to have a half life of 18 days in non-vitrectomised eyes. ${ }^{18}$ Gillies et al estimated that significant levels of iTAAC are likely to persist inside the eye for at least 4 months. ${ }^{16}$ However, their study evaluated the effect of a single $4 \mathrm{mg}$ iTAAC, due to potential severe side effects following a second iTAAC. Henceforth, Gillies and Luo found that the incidence of adverse events after a second iTAAC is similar to a single one as long as there is an interval of at least 4 months between the two injections. ${ }^{16}$ The side effects found in the present study were transient IOP elevation, requiring antiglaucoma medication in one patient, and a progression of existing cataract in $50 \%$ of phakic eyes. IOP elevation prevalence in this study $(28.5 \%)$ is in the range of previous studies $(25 \%-41.3 \%) .{ }^{13}{ }^{16}$ In the present study, cataract progression was observed in $50 \%$ of phakic eyes, similar to one of our group's previous studies. ${ }^{13}$ However, cataract was not found to be a triamcinolone related adverse event during the first year in Gillies et al's study as we had found in another of our studies. ${ }^{76}$ Although Gillies et al's study did not find a single $4 \mathrm{mg}$ iTAAC to have a beneficial effect on vision during the first year, they did find a benefit in regard to lesion size at 3 months $(p=0.01){ }^{16}$ Therefore, they raised the possibility that a higher dose of iTAAC administered more frequently, or in combination with other treatments such as PDT, might be efficacious in AMD treatment. ${ }^{16}$

The results of the current study should be evaluated with caution. It is necessary to evaluate this combination therapy in a much larger population, preferably, in a multicentre, masked, and placebo controlled trial. The treatment protocol in such a study may recommend repeating combined treatment at the 6 months visit in case there is an active lesion at that time. Only a well designed study will provide us with the information suitable for evidence based decision making regarding this combined treatment.

\section{Authors' affiliations}

E Rechtman, R P Danis, L M Pratt, A Harris, Department of Ophthalmology, Indiana University School of Medicine, Indianapolis, IN, USA

E Rechtman, Department of Ophthalmology, Kaplan Medical Center, Rehovot, Israel

R P Danis, Department of Ophthalmology and Visual Sciences, University of Wisconsin Medical School, Madison, WI, USA

Correspondence to: Dr R P Danis, Department of Ophthalmology and Visual Sciences, University of Wisconsin Medical School, Park West One, 406 Science Drive, Suite 400, Madison, WI, 53711-1068, USA; rdanis@rc.ophth.wisc.edu; ehudrechtman@yahoo.com

Accepted for publication 18 August 2003

\section{REFERENCES}

1 Photodynamic therapy of subfoveal choroidal neovascularization in agerelated macular degeneration with verteporfin: one-year results of 2 randomized clinical trials - TAP report. Treatment of age-related macular degeneration with photodynamic therapy (TAP) Study Group. Arch Ophthalmol 1999;117:1329-45.

2 Bressler NM. Photodynamic therapy of subfoveal choroidal neovascularization in age-related macular degeneration with verteporfin: twoyear results of 2 randomized clinical trials-TAP report 2. Arch Ophthalmol 2001; 119:198-207.

3 Verteporfin therapy of subfoveal choroidal neovascularization in age-related macular degeneration: two-year results of a randomized clinical trial including lesions with occult with no classic choroidal neovascularization-verteporfin in photodynamic therapy report 2. Am J Ophthalmol 2001;131:541-60.

4 Verteporfin therapy of subfoveal choroidal neovascularization in patients with age-related macular degeneration Additional information regarding baseline lesion composition's impact on vision outcomes. TAP Report No. 3. Arch Ophthalmol 2002;120:1443-54.

5 Argon laser photocoagulation for neovascular maculopathy. Five-year results from randomized clinical trials. Macular Photocoagulation Study Group. Arch Ophthalmol 1991;109:1109-14.

6 Laser photocoagulation of subfoveal neovascular lesions of age-related macular degeneration. Updated findings from two clinical trials. Macular Photocoagulation Study Group. Arch Ophthalmol 1993; 111:1200-9.

7 Ranson NT, Danis RP, Ciulla TA, et al. Intravitreal triamcinolone in subfoveal recurrence of choroidal neovascularisation after laser treatment in macular degeneration. Br J Ophthalmol 2002;86:527-9. 
8 Ciulla TA, Criswell MH, Danis RP, et al. Intravitreal triamcinolone acetonide inhibits choroidal neovascularization in a laser-treated rat model. Arch Ophthalmol 2001;199:399-404.

9 Danis RP, Bingaman DP, Yang Y, et al. Inhibition of preretinal and optic nerve head neovascularization in pigs by intravitreal triamcinolone acetonide. Ophthalmology 1996;103:2099-104.

10 Tano Y, Chandler D, Machemer R. Treatment of intraocular proliferation with intravitreal injection of triamcinolone acetonide. Am J Ophthalmol 1980:90:810-16

11 Antoszyk AN, Gottlieb JL, Machemer R, et al. The effects of intravitreal triamcinolone acetonide on experimental pre-retinal neovascularization. Graefes Arch Clin Exp Ophthalmol 1993;231:34-40.

12 Folkman J, Ingber DE. Angiostatic steroids. Method of discovery and mechanism of action. Ann Surg 1987;206:374-83.

13 Danis RP, Ciulla TA, Pratt LM, et al. Intravitreal triamcinolone acetonide in exudative age-related macular degeneration. Retina $2000 ; 20: 244-50$
14 Penfold PL, Gyory JF, Hunyor AB, et al. Exudative macular degeneration and intravitreal triamcinolone. A pilot study. Aust N Z J Ophthalmol 1995;23:293-8.

15 Challa JK, Gillies MC, Penfold PL, et al. Exudative macular degeneration and intravitreal triamcinolone: 18 month follow up. Aust N Z J Ophthalmol 1998;26:277-81.

16 Gillies MC, Simpson JM, Luo W, et al. A randomized clinical trial of a single dose of intravitreal triamcinolone acetonide for neovascular age-related macular degeneration: one-year results. Arch Ophthalmol 2003;121:667-73.

17 Jonas JB, Kreissig I, Hugger $\mathrm{P}$, et al. Intravitreal triamcinolone acetonide for exudative age related macular degeneration. $\mathrm{Br} J$ Ophthalmol 2003:87:462-8.

18 Bakri SJ, Beer PM, Singh RJ, et al. Pharmacokinetics of intravitreal triamcinolone acetonide. [Ábstract]. America Academy of Ophthalmology 2002:157. 19 Wingate RJ, Beaumont PE. Intravitreal triamcinolone and elevated intraocular pressure. Aust N Z J Ophthalmol 1999;27:431-2. 